REJ - Revista de Estudios de la Justicia - No 9 - Año 2007

\title{
MENORES DE EDAD EN LA JURISPRUDENCIA DE LA CORTE SUPREMA DE EE.UU.*
}

Gonzalo Paredes $S$.

Tarek Yúsari K.**

\begin{abstract}
Introducción; Los crimenes; I. Entre la pena de muerte y la cadena perpetua; a) Los rasgos de los jóvenes y la proporcionalidad; b) Las consecuencias para los fines de la pena; c) La propuesta de Kennedy; II. Hacia el Fundamento de la Culpabilidad: Peligrosidad y la Realidad en los Death Rows; i. La "inmadurez" como agravante; ii. Niñer. y Adulter: el discernimiento; iii. Los Estudios; iv. La Disuasión; v. La dinámica de la alta penalidad juvenil; III. Derecho Penal y Culpabilidad: El fundamento de la exigencia; i. La exigencia; ii. Culpabilidad, Proporcionalidady Retribución; iii. Pena y Persuasión; iv. Los fundamentos de Justicia; IV. Conclusión.
\end{abstract}

\section{INTRODUCCION}

Según Michael Moore ${ }^{1}$, el Derecho Penal sirve a la justicia retributiva. En orden a satisfacer los requerimientos de justicia retributiva que busca alcanzar el Derecho Penal, éste debe castigar a todos los que sean y, sólo los que sean, moralmente culpables en la comisión de una acción moralmente mala. De este modo, la parte general del Derecho Penal sería la encargada de establecer aquellas condiciones que sirven para definir tanto aquellas conductas, como la culpabilidad.

Siguiendo al mismo autor estadounidense, una teoría de la responsabilidad (penal), puede ser dividida en tres partes, a saber: en primer lugar, una teoría de la responsabilidad propiamente tal, la cual establece las condiciones que deben encontrarse presentes antes de que pueda sindicarse a alguien moralmente responsable en un sentido relevante; la segunda parte es aquélla que dice relación con las diversas sub-teorías que tratan la naturaleza de aquellas condiciones de responsabilidad; por último, en tercer lugar, Moore afirma que estos elementos de la responsabilidad sólo pueden tener dicha naturaleza en tanto las personas tengan una determinada naturaleza. Por lo tanto, la tercera teoría que se necesita es una acerca de la personalidad. Es así como el Derecho Penal se ve en la necesidad de contar con una teoría acerca de cómo debe ser aquel sujeto que es capaz de tener aquellas cualidades que hacen posible imputarle ciertas condiciones de atribución de responsabilidad. Una teoría de la responsabilidad es, entre otras cosas, una teoría sobre las personas.

\footnotetext{
* Este artículo es fruto de un trabajo elaborado para el curso Derecho Público Punitivo Comparado dictado por Antonio Bascuñán Rodríguez. Agradecemos al profesor Bascuñan por un iluminador y valioso curso. Además, agradecemos a Francisco Javier Urbina y a Francisco Saffie por comentarios y sugerencias hechas a una versión preliminar de éste.

** Estudiantes de $5^{\circ}$ año. Facultad de Derecho, Universidad de Chile.

${ }^{1}$ Moore, Michael, Placing Blame, Oxford University Press, New York, 1997.
} 
Paredes y Yusari - Menores de edad en la jurisprudencia de la Corte Suprema de EE.UU.

Esta imputación, en tanto construcción normativa, se comprende como un proceso en el cual se atribuye un sentido determinado a un fenómeno acaecido en la realidad. Por ende, este proceso se encuentra necesaria e íntimamente conectado con los paradigmas y valoraciones dominantes en un contexto social determinado. En el mismo sentido, Hassemer ${ }^{2}$ reconoce dos presupuestos centrales para la posibilidad y justificación de la imputación de un hecho a una persona: el primero de ellos dice relación con la idea de que el mundo está gobernado por personas. Es evidente que un gran número de acontecimientos que se vivencian diariamente escapan de cualquier tipo de control por parte de los seres humanos; sin embargo, aún son muchas las cosas que dependen de la voluntad del hombre. El segundo de dichos presupuestos es que las personas pueden ser consideradas responsables de sus acciones y de las consecuencias que se deriven de éstas. Así, achacarle una sanción a un sujeto puede efectivamente considerarse como el reproche por alguna conducta que estaba dentro de sus posibilidades omitir (o realizar en el caso de que se le reproche su omisión). Por tanto, se debe tener una idea clara de quiénes pueden ser responsabilizados de sus actos, en especial atención a la particular naturaleza lesiva del Derecho Penal.

Al discurrir acerca de los sujetos capaces de imputación nos encontramos de frente con el concepto de culpabilidad. En un primer término, este concepto funciona, en su sentido formal, como una categoría de atribuibilidad. Esto se refiere a las posibilidades del sujeto de incorporar a la norma como una razón relevante dentro de su proceso decisorio a la hora de realizar una conducta antijurídica, conceptualizándose la culpabilidad en este sentido como la no incorporación de la norma en un sentido relevante. En otras palabras, el concepto de culpabilidad formal dice relación con el contenido del reproche, es decir, el examen de las circunstancias que permiten considerar a un sujeto como culpable de la infracción de una norma de comportamiento. En este sentido, no son relevantes las consideraciones acerca de la validez de las normas, ni menos la pregunta por el fundamento de la obligatoriedad de éstas. El concepto formal de culpabilidad no se mueve en dicho ámbito. Es evidente sin embargo, que a este proceso de imputación debe subyacer una teoría acerca de estas dos cuestiones, en especial de la última. Así, se trabaja ya habiéndose decidido con anterioridad acerca del vínculo que se exige entre sujeto y norma y la legitimidad de esta exigencia. Por esto, la posibilidad de incorporar la norma dentro del proceso de decisión del sujeto debe suponer necesariamente la existencia de un vínculo entre el sujeto y la norma, donde esta posibilidad de vínculo se fundamenta en la concepción de la persona que subyace al Derecho. En este punto, el debate escapa del ámbito jurídico-normativo y pasa a radicarse en el plano de la justicia política, puesto que se pregunta tanto por la legitimidad de la relación entre sujeto y norma, como por la determinación de aquellas condiciones necesarias y suficientes para que se pueda exigir justificadamente dicha relación. Lo anterior contrasta con la culpabilidad formal, que da por supuestas las condiciones individuales del agente y analiza las

\footnotetext{
2 Hassemer, Winfried, "Persona, Mundo y Responsabilidad”, en Persona, Mundo y Responsabilidad. Bases para una Teoría de la Imputación en el Derecho Penal, Ed. Temis (Santa Fe de Bogotá) 1999, p. 102.
} 
circunstancias particulares en las que se puede sustentar una determinada no exigibilidad de conducta (justificación y disculpa). Es a partir del establecimiento de los sujetos inimputables, a los cuales no se les exige vinculación con la norma, dónde hay que comenzar a desentrañar la teoría del sujeto subyacente. En definitiva y, parafraseando a Kindhäuser ${ }^{3}$, lo que en este momento se pregunta es quiénes son aquellos sujetos a los que puede exigirse legítimamente la obediencia al sistema normativo mediante la necesidad de incorporación de la norma en un sentido relevante.

En orden a contestar esta pregunta, no se pueden dejar de lado consideraciones fácticas acerca de las características que deben poseer los agentes para ser sujetos de imputación, capaces de culpabilidad. Para fundar una exigencia de obediencia al Derecho, debe responderse previamente la pregunta acerca de aquellos elementos empíricos que deben estar presentes en el sujeto, en orden a que le sea posible cumplir con aquella exigencia.

En este artículo se discutirá acerca de la penalización y consiguiente punición de los menores de edad mediante el examen crítico de algunas sentencias de la Corte Suprema estadounidense, en particular el caso difícil y límite de los adolescentes, donde es necesario discernir cuáles son los fundamentos de justicia que subyacen a la consideración de éstos como sujetos capaces de culpabilidad de manera similar a los adultos, situación que se extiende incluso a los pre-púberes en la realidad estadounidense.

En relación con lo anterior, cabe caracterizar tanto a la pena como a la culpabilidad como expresiones de sentido. Incluso, dentro del medio estadounidense, Joel Feinberg ${ }^{4}$ le ha atribuido justamente a la pena la función de expresar un sentido. La norma penal, en su carácter de acto de habla, pretende en su dimensión ilocucionaria, interpelar a los sujetos obligados para que la incorporen como motivo válido de actuación, por lo que las condiciones personales de aquel imperado por la norma son fundamentales en orden a que la norma consiga éxito en dicha dimensión. Además, lo cual trasunta también del razonamiento de la Corte en los casos que posteriormente se analizarán, dichas condiciones personales son también fundamentales a la hora de la obtención de éxito perlocucionario, en términos de obediencia fáctica de la norma en cuestión.

A raíz de lo expuesto, debemos cuestionarnos acerca de ese mínimo empírico que subyace al pensamiento de la Corte que permite a los adolescentes ser sujetos del sistema penal, muchas veces en igualdad de condiciones que los adultos, pudiendo ser achacados con las penas más altas del sistema como la

\footnotetext{
${ }^{3}$ Kindhäuser, Urs, "La Fidelidad al Derecho como Categoría de Culpabilidad", en Revista Peruana de Doctrina y Jurisprudencia Penal, Lima, 2000.

${ }^{4}$ Feinberg, Joel, "The Expressive Function of Punishment", en Doing and Deserving: Essays in the Theory of Responsibility, 1970 citado en: De Grieff, Pablo, "Deliberative Democracy and Punishment", Buffalo Criminal Law Review, Vol. 5:373, 2002.
} 
Paredes y Yusari - Menores de edad en la jurisprudencia de la Corte Suprema de EE.UU.

cadena perpetua efectiva sin posibilidad de libertad condicional (en ingles LWOP: "life without parole") o incluso la pena capital. Así, es relevante en qué dimensión del individuo se fundamenta la exigencia de vinculación con el Derecho. En base a lo anterior, también es necesario discernir acerca de si efectivamente se exige al adolescente un cierto vinculo con la norma penal o si en su lugar o, al menos de manera más explicita, la exigencia está dirigida a otras consideraciones.

Para ello, se discutirá en un primer término acerca del alcance del requisito de proporcionalidad supuestamente presente en la VIII Enmienda de la Constitución Federal de EE.UU., para luego apuntar al tratamiento de la proporcionalidad que se realiza por la Corte, con miras a ir desentrañando la concepción, contenido y fundamento de la culpabilidad presente en las dos tendencias al interior de ésta. Por último, se intentará una crítica y reflexión general acerca de los fundamentos de la responsabilidad penal de los adolescentes.

\section{Los Crímenes ${ }^{5}$}

\section{Thompson v. Oklahoma (487 U.S. 815 1988)}

El joven Thompson de 15 años de edad asesinó a su cuñado, motivado aparentemente por los maltratos físicos propinados a su hermana.

Antes de cometer el crimen, el acusado manifestó a su novia la intención de matar a la víctima. Thompson, junto con 3 cómplices, golpearon con pies y puños a la víctima -además de un objeto contundente- mientras se le mantenía amenazada con una escopeta. Luego, subieron a la víctima a un auto y se marcharon con dirección al río Washita. Allí, le dispararon dos veces en la cabeza y le cortaron la garganta, pecho y abdomen, para luego arrojarlo al río con una cadena y bloques de cemento "para que los peces pudieran comer su cuerpo". En los días posteriores, Thompson realizó diversas declaraciones relativas al crimen, confesando su participación en los hechos sin mostrar rastros de remordimiento.

De acuerdo a la legislación estadual, Thompson fue juzgado como como adulto y condenado a la pena capital. La Corte Suprema de los Estados Unidos, en certiorari, revocó la pena.

\section{Stanford v. Kentucky (492 U.S. 361 1989)}

El recurrente Kevin Stanford y su cómplice, ambos de 17 años, asesinaron a una joven de 20 años, luego de sodomizarla y robar la bomba de bencina donde trabajaba. Después de violarla, fue conducida a un área solitaria cercana, donde le dispararon a quemarropa en la cara y nuca. El botín consistió en 300 cartones de cigarrillos, dos galones de bencina y un poco de dinero en efectivo.

Stanford, en una de sus declaraciones ante un oficial de la correccional testificó, en medio de carcajadas: "Le disparé, vivía cerca mío y me

\footnotetext{
${ }^{5}$ Las siguientes 2 páginas son una relación de los casos, con el objeto de situar el tema.
} 
reconocería...creo que pudimos haberla atado y golpearla, amenazándola con matarla para el caso de que nos delatara".

Al ser mayor de 16 años y haber cometido un crimen capital, fue juzgado como adulto según la legislación del estado, siendo condenado a muerte. La Corte Suprema de los Estados Unidos confirmó dicha condena.

Junto con el caso de Stanford, se presentó el del joven Wilkins, quien apuñaló a una mujer de 26 años y madre de dos hijos, causándole la muerte. Ella se desempeñaba en la tienda que dirigía junto a su marido. Según el expediente, el joven se disponía a asesinar a cualquier persona que se encontrara dentro de la tienda, para evitar que lo delatase.

Mientras su cómplice sujetaba a la víctima, Wilkins la apuñaló. Su cómplice tenía problemas operando la caja registradora, por lo que la víctima intentó ayudarlo. Ante esto, Wilkins la apuñaló tres veces más en el pecho, atravesando su corazón. Al rogar por su vida, la mujer fue apuñalada cuatro veces más en el cuello, cercenándole la arteria carótida.

Luego de extraer alcohol, cigarrillos y cuatrocientos cincuenta dólares en efectivo y cheques, se marcharon dejando a la mujer agonizante en el piso. La ley del estado de Kentucky permite que individuos de entre catorce y diecisiete años de edad sean juzgados como adultos en este tipo de crímenes. También fue condenado a muerte, siendo confirmado por la Corte Suprema.

\section{Roper v. Simmons (543 U.S. 551 2005)}

A la edad de diecisiete años, el recurrido Christopher Simmons asesinó a una mujer. Antes de los hechos confesó su intención de matar a alguien, discutiendo en fríos términos sobre su plan principalmente con dos amigos de quince y dieciséis años. Simmons se proponía robar y asesinar, ingresando por la fuerza a un lugar habitado, para luego amarrar a su víctima y lanzarla desde un puente. Suponía poder salir impune por ser menor de edad.

Simmons junto a uno más de ellos, forzaron la entrada a una casa. Al encender la luz de la habitación principal, el joven reconoció a una mujer con quien se había visto involucrado en un accidente automovilístico, confirmando su intención de asesinarla.

La maniataron con cinta adhesiva, tapando ojos y boca, llevándola en automóvil a un parque estatal. En este lugar, ataron sus manos y pies con cables eléctricos, cubrieron su cabeza con una toalla, taparon toda su cara con cinta adhesiva y la lanzaron al río Meramac.

Al día siguiente la víctima fue encontrada por pescadores. Mientras tanto, Simmons alardeaba sobre su crimen entre sus amigos.

La jurisdicción juvenil del estado de Missouri permitió que Simmons fuese juzgado como adulto, siendo condenado a muerte. La defensa de Simmons apeló, argumentando el razonamiento de Atkins v. Virginia, precedente que impidió la ejecución de un criminal con retardo mental. La Corte Suprema estadual revocó la sentencia y la federal confirmó la decisión de la corte estadual. 
Paredes y Yusari - Menores de edad en la jurisprudencia de la Corte Suprema de EE.UU.

\section{Entre la Pena de Muerte y la Cadena Perpetua}

\section{a) Los rasgos de los jóvenes y la proporcionalidad}

El juez Kennedy, expresando la opinión de la mayoría en Roper v. Simmons (543 U.S. 551 2005) busca configurar la menor reprochabilidad moral de los adolescentes por sus conductas. La falta de madurez en los jóvenes se traduce en un subdesarrollo de su nivel de personalidad, lo que los inclina a la realización de acciones impulsivas y sin adecuada consideración acerca de sus consecuencias e implicancias. Lo anterior se explica en parte por su mayor vulnerabilidad ante las influencias negativas o presiones externas, dificultándoles en comparación a los adultos la labor de abstraerse de contextos criminógenos.

A juicio del mencionado juez, lo anterior no es de todos modos, gravemente preocupante. Los jóvenes se encuentran en un proceso de formación de personalidad, por lo que sus rasgos son transitorios y flexibles ante los intentos de reforma. Así, en su mayoría, las conductas antisociales o riesgosas son pasajeras, cesando al alcanzar la madurez y la fijación de la identidad individual. Por ello, siguiendo las ideas de Kennedy, el crimen -no obstante su atrocidad- no es un indicio seguro de una personalidad irreversiblemente depravada, haciendo al sujeto menos peligroso. Por lo tanto, junto con otras consideraciones que se expondrán más adelante, la pena de muerte es injustificada.

En base a la constatación de dicho proceso de formación, se puede desprender del argumento de la Corte la mayor posibilidad de reforma y rehabilitación en los adolescentes. Las mismas cualidades que disminuyen su reprochabilidad moral sirven para legitimar su tratamiento por parte del sistema. La carencia de madurez los dota de menos autonomía que un adulto, por lo que la intervención por parte del Estado en su formación puede ser difícilmente catalogada como paternalismo al no concretarse ataque a autonomía ya que ésta, en sentido relevante, no está presente. La misma negación de autonomía o libertad que se utiliza para fundamentar su sustracción de una pena muy severa, legitima la posibilidad de intervenirlos o tratarlos.

Lo anterior constituye un primer intento por parte de Kennedy de elaborar un estándar de culpabilidad que sirva para fundar un juicio de proporcionalidad retrospectivo. La Corte reconoce así la necesidad de dicho criterio al incluir en Simmons parte del razonamiento de Atkins v. Virginia (536 U.S. 304 2002), estableciendo que la pena capital debe limitarse sólo a aquellos criminales que comenten una estrecha categoría de los crímenes más serios y a quienes cuya extrema culpabilidad los hace más merecedores de la ejecución. Por ello, en cualquier caso capital el acusado tiene un amplio margen para alegar como factores atenuantes cualquier aspecto de su carácter o bistorial, además de cualquier circunstancia del delito que estime adecuada para fundamentar una pena inferior a la muerte (extraído a su vez de Lockett v. Obio 438 U.S. 586 1978). Este punto se ve refrendado en Coker v. Georgia (433 U.S. 584 1977) en que cierta clase de crímenes 
REJ - Revista de Estudios de la Justicia - No 9 - Año 2007

pueden ser catalogados como severos en términos absolutos, sin embargo la pena de muerte no puede ser impuesta.

\section{b) Las consecuencias para los Fines de la Pena}

Los jueces tienen a la vista básicamente dos fines de la pena, a saber: retribución y disuasión o intimidación (prevención general negativa).

En lo concerniente a la retribución, el juez Kennedy a partir de Atkins v. Virginia sostiene que en general la culpabilidad del asesino promedio es insuficiente para fundamentar la aplicación de la sanción más extrema del sistema, por lo que - a fortiori- la menor culpabilidad de los adolescentes no puede ameritar retribución al extremo de la ejecución. De este modo, sea vista la pena como medio de expresión de indignación moral o equiparación del mal de la víctima, Kennedy estima la muerte como desproporcionada.

Se puede sostener que existe el convencimiento en Kennedy que la sociedad tiene expectativas menores en los adolescentes, por lo que el nivel de indignación es igualmente menor. Los adolescentes carecerían de ciertos atributos para formar junto con los adultos del grupo acerca del cual se tienen expectativas relacionadas con el cumplimiento de ciertas normas.

Por el lado de la disuasión, las mismas consideraciones relativas a la psicología de los jóvenes hacen dudar acerca de una influencia significativa o siquiera mensurable de la conminación con pena de muerte. A pesar de no hacer extensible el argumento a la totalidad de los individuos (como modernamente se sostiene), Kennedy reconoce que los adolescentes no se embarcan en cálculos de tipo costo - beneficio a la hora de determinar la comisión de un hecho punible, disminuyendo considerablemente la eficacia disuasiva de la conminación penal. Por lo tanto, en un argumento de necesidad afirma que no se justifica un medio tan severo de intervención dado que, ante la duda de su eficacia por ciertos caracteres empíricos de los jóvenes, se inclina por una pena -a su juicio- menos lesiva.

Considerando por una parte la menor reprochabilidad moral de los jóvenes en atención a su inmadurez y, por otra, las consecuencias de ello en la eficacia disuasiva de la pena de muerte, se desprende que la norma en el caso de los jóvenes no pretende un mayor éxito ilocucionario en términos comunicativos, puesto que los argumentos anteriores se centran solamente en la posibilidad de intimidar mediante la amenaza de sanción, en lugar de obtener una efectiva fidelidad del sujeto a la norma de comportamiento. En Roper no se les reconoce a los jóvenes aquella densidad moral o madurez necesaria para acceder a un estadio comunicativo más exigente o sofisticado. Por ello, la función de prevención general negativa se configura en atención al sujeto como instrumentalizable estratégicamente a fin de que se abstenga de dañar estados de cosas valiosos en 
Paredes y Yusari - Menores de edad en la jurisprudencia de la Corte Suprema de EE.UU.

sociedad. Sin embargo, tampoco son los suficientemente instrumentalizables por carecer de esos mismos atributos que los hacen menos reprochables.

\section{c) La Propuesta de Kennedy}

En conclusión, Kennedy afirma que la pena de muerte resulta desproporcionada. En un primer término, lo fundamenta retrospectivamente habida consideración de la menor culpabilidad (reprochabilidad moral) de los adolescentes a consecuencia de sus rasgos de personalidad. Sin embargo, esas mismas consideraciones lo asisten a la hora de sostener también la desproporcionalidad desde una óptica prospectiva tomando en cuenta la eficacia disuasiva de la pena capital. Así, dado que la VIII Enmienda exige el examen de proporcionalidad (tesis controvertida por otro sector de los jueces), se torna ilegítima la imposición de la pena más grave del sistema a "aquellos sujetos que, como categoría, no pueden ser ubicados dentro de los peores criminales o más atroces.

Por lo tanto, dicho juez presenta a la LWOP como la pena adecuada. Sin embargo, una pena privativa de libertad como esta también sería desproporcionada siguiendo los argumentos de Kennedy. Él afirma que a un adolescente se le puede privar de sus libertades básicas como sanción por su conducta, pero no se le puede extinguir mediante la muerte aquella posibilidad de desarrollarse y madurar a fin de obtener aquellas cualidades morales propias de un adulto responsable y fiel a las exigencias morales de la sociedad. Puesto que, como se mencionó, el crimen adolescente no es necesariamente indiciario de una personalidad irreversiblemente depravada, debe existir la posibilidad de que recapacite y logre formar plenamente su personalidad.

Este mismo razonamiento es aplicable a la LWOP o a cualquier otra privación de libertad de una magnitud considerable. La LWOP también priva al joven de adquirir aquellos rasgos que Kennedy atribuye a la adultez. No extingue su vida (presupuesto necesario de dicho proceso), pero de todos modos la ausencia de libertad elimina las condiciones indispensables de maduración y desarrollo de carácter. Otra pena privativa de libertad de menor envergadura lo más probable es que consolide en el adolescente la personalidad negativa que se esperaba inestable y pasajera. Por lo tanto, se asegura a la sociedad de la peligrosidad del joven a costa de impedirle alcanzar las metas que Kennedy estima esenciales en la formación del individuo. Ciertamente seguirá viviendo, pero difícilmente desarrollará su personalidad como se espera, sea que permanezca en la cárcel para siempre o salga en libertad. De hecho, en Hampton v. Kentucky (666 S.W. 2d 1984), la Corte Suprema de Kentucky sostuvo: "La LWOP para un adolescente, al igual que la muerte, es una sentencia diferente en cualidad y carácter que una sentencia a un determinado término de años sujetos a libertad condicional'. Además, dadas las características del sistema estadounidense, lo más probable es que el menor sea parte del mismo sistema penal adjudicativo y penitenciario que los adultos. 
La coherencia exige a Kennedy, si quiere llevar el argumento de la prevención especial más allá de la inocuización o aislamiento, sustentar penas distintas a la muerte o privación de libertad. En su lugar, debiese plantear algo similar al servicio a la comunidad o simplemente salirse del ámbito penal adulto y asumir algún tipo de intervención de rehabilitación por instalaciones sociales adecuadas. Incluso, el solo sometimiento del menor al sistema penal adulto, con sus rasgos de lesividad intensificada característicos, podría quedar desacreditado por los mismos argumentos en atención a sus efectos en la personalidad del adolescente.

\section{Hacia el Fundamento de la Culpabilidad: Peligrosidad y la Realidad en los Death Rows}

\section{i. La "inmadurez" como agravante}

Frente a las pretensiones de Kennedy y la mayoría en Roper de declarar la inconstitucionalidad de la pena de muerte para los menores de 18 años, la jueza O' Connor plantea la opción de dejarle a cada jurado la evaluación caso a caso de la personalidad del joven en orden a determinar un merecimiento de reproche suficiente para fundar la aplicación de la pena capital. La jueza sostiene que, no obstante poder afirmarse que, como categoría, los jóvenes tienen una culpabilidad disminuida, algunos pueden ser considerados especialmente maduros y culpables para ser ejecutados.

Ante esto, Kennedy responde que existe la posibilidad de que el peso otorgado a la atrocidad del crimen o circunstancias similares pueda sobrepasar la consideración adecuada a la juventud del sujeto, posibilidad que existe cuando se les deja la opción a los jurados para que determinen en cada caso particular la madurez del menor. Por esto, la inmadurez, vulnerabilidad y falta de auténtica "depravación" podrían pasar a segundo plano a ojos del jurado. Incluso, la juventud podría ser utilizada como agravante. Así, el fiscal encargado de sustentar la acusación contra el joven Simmons, señaló en sus argumentos de cierre: "La edad, él dice. Piensen acerca de la edad. 17 años de edad. ¿No es acaso atemorizante? ¿No los asusta? ¿Atenuante? Muy por el contrario creo yo, muy por el contrario..." Lo anterior, sumado a la constatación de que Simmons tenía una personalidad altamente inmadura, impulsiva y bastante susceptible de ser influida o manipulada, terminaron por convencer al jurado de que su culpabilidad ameritaba la imposición de la pena de muerte. Se puede decir que lo realmente relevante fueron las consideraciones acerca de la peligrosidad, comprendiéndose como parte de la culpabilidad por el hecho. Se debe notar de todos modos cómo el debate de aleja de la culpabilidad al momento de la comisión y se acerca al futuro riesgo de la sociedad al no incapacitar al individuo en cuestión.

En Stanford v. Kentucky (492 U.S. 361 1989) el juez Brennan aporta ciertos datos en la opinión de minoría en relación con lo anterior, afirmando que no es 
Paredes y Yusari - Menores de edad en la jurisprudencia de la Corte Suprema de EE.UU.

sorprendente que la consideración individualizada al momento de transferir a la jurisdicción adulta y de sentenciar al menor, no haya asegurado en los hechos que los delincuentes juveniles carentes de una culpabilidad adulta no sean sentenciados a muerte. Muy por el contrario, los adolescentes condenados a muerte aparecen típicamente como sujetos con un cúmulo de problemas psicológicos, emocionales y otros que se relacionan intimamente con su capacidad de juicio y nivel de reprochabilidad moral. Para sustentar lo anterior, cita una evaluación a 14 jóvenes condenados a muerte en cuatro estados distintos, cuyos resultados son bastante ilustrativos. Así, resultó ser que siete de los adolescentes condenados a muerte eran sicóticos a la hora de ser evaluados o habían sido diagnosticados en una temprana infancia; otros cuatro tenían historias consistentes con diagnósticos de severos desórdenes de ánimo y personalidad; y los tres restantes habían experimentado episodios paranoicos periódicos, durante los cuales habrían atacado a quienes consideraban enemigos. Por otra parte, ocho de ellos habían sufrido lesiones severas en su niñez y nueve sufrían anormalidades neurológicas. Por su parte, pruebas psico-educacionales arrojaron que sólo dos de estos jóvenes condenados a muerte poseían coeficientes intelectuales superiores a 90 (rango normal), pero ambos sufrían de desórdenes siquiátricos, mientras que 10 de ellos mostraron limitaciones de razonamiento abstracto en diversas pruebas. Además, todos salvo dos habían sido abusados físicamente y 5 abusados sexualmente. Por último, era común encontrar en las familias de estos sujetos la presencia de violencia, alcoholismo, drogadicción y desórdenes siquiátricos.

\section{ii. Niñez y Adultez: el discernimiento}

Para la mayoría de la Corte, las edades legales establecidas para votar, beber, conducir o adquirir pornografía, demuestran cómo la sociedad dibuja la línea entre la adultez y la niñez en los 18 años. Ante esto, el juez Scalia afirma en Stanford v. Kentucky que es "absurdo pensar que uno tiene que ser suficientemente maduro para manejar con cuidado, tomar responsablemente, o votar inteligentemente en orden a ser suficientemente maduro para entender que asesinar a otra persona es profundamente malo y equivocado y para conformar la propia conducta a los estándares de civilidad más minimos". Tanto en el caso de Simmons, como en Stanford y Thompson, Scalia cita estudios a fin de afirmar que "al llegar a la media adolescencia, (entre 14 y 15 años), los jóvenes desarrollan habilidades similares a los adultos en el razonamiento acerca de dilemas morales, comprensión de las reglas sociales y las leyes y razonamiento acerca de relaciones y problemas interpersonales...". Por lo tanto, desde el punto de vista de Scalia, los argumentos y estudios ofrecidos por la mayoría de la Corte en Roper no ofrecen sustento suficiente a una prohibición categórica de la pena de muerte para los asesinos menores de 18 años. A lo más, los estudios demostrarían que en promedio dicha categoría de individuos son incapaces de asumir la debida responsabilidad moral. Es más, la mayoría sería capaz de apreciar la naturaleza de sus crímenes.

Como se puede observar hasta este punto del desarrollo, se puede afirmar que, a pesar de que Kennedy y Scalia (en tanto representativos de dos posiciones opuestas en la Corte) difieren en cuanto a la culpabilidad de los menores de edad, ambos tienen una coincidencia importante. En su debate se halla el fundamento de 
la exigibilidad de los menores a adecuarse a la normativa moral y penal. Pareciera ser que para ambos el fundamento de la responsabilidad juvenil radica en ciertas capacidades morales más bien básicas que permiten al sujeto discernir la bondad de la maldad y comprender los daños que producen, entendiendo lo que implican las relaciones intersubjetivas presentes al cohabitar el mundo con otras personas. Así, la imputabilidad (tal como se hace en Estados Unidos) ${ }^{6}$ se puede afirmar incluso de los pre-púberes por cuanto son capaces de discernir entre bondad y maldad de ciertos actos. En lo que difieren simplemente es en la graduación de distintos niveles de responsabilidad (culpabilidad) en atención a las características que estiman relevantes y presentes en cada estadio del desarrollo personal.

Probablemente, todos los condenados de las estadísticas presentadas por Brennan eran capaces de distinguir lo bueno de lo malo y comprender (al menos toscamente) la dañosidad de sus conductas, además de satisfacer en cada uno de sus delitos los requisitos del mens rea. Sin embargo, cabe preguntarse si puede razonablemente sindicarse a estos individuos como culpables en un sentido moralmente relevante, más allá de cierto vínculo psicológico con los hechos. Lo afirmado especialmente por Scalia parece ser un requisito bastante bajo para justificar de manera legítima la exigencia que implica ser sujeto del sistema penal. No forma parte del debate de manera central la consideración en torno a la posición que toma el menor frente a lo que se le aparece gracias a aquellas capacidades y habilidades mentales que posee desde una primera juventud. Lo relevante, más que el discernimiento y la posibilidad de premeditación y ejecución del acto (queriendo y sabiendo) debe ser algo más complejo. En el mismo sentido, se sostuvo en Coker v. Georgia (433 U.S. 584 1977) que el retardo mental disminuye la culpabilidad personal, a pesar de que pueda distinguir lo bueno de lo malo. Por tanto lo relevante no es la distinción, sino que el impacto de ésta en el actuar del sujeto. En caso contrario, la inimputabilidad estaría consagrada únicamente para aquellas personas que no pudiesen diferenciar bondad de maldad debido a una severa incapacidad cognitiva, alcanzando solamente a una fracción de la gente con discapacidad mental. Así, la posibilidad de apreciar la maldad del acto se presume la circunstancia de poder conformarse al mandato de la ley.

\footnotetext{
${ }^{6}$ En la Corte no se debate la condición de imputables de los menores de edad, girando la discusión solamente acerca del lugar que les corresponde en la justicia penal juvenil o adulta. Lo controvertido en la Corte es la existencia de una culpabilidad disminuida en los adolescentes y la correspondencia de la pena de muerte en atención a esto. La criminalización no es objeto de debate en la Corte ni en la doctrina. Incluso en Washington se aplica sin restricción la legislación criminal a menores de 8 años de edad. Es un principio del common law que los menores de 14 años no son capaces de mens rea necesario para cometer un delito.

7 Por consideraciones de espacio, se debió omitir de la versión final de este artículo una explicación de dicho concepto. Para ello, ver Dressler, Joschua, Understanding Criminal Law, $3^{a}$ Edición, Ed. Lexis Publishing (New York) 2001, p. 115 y ss. Además se examinaba una confusión conceptual presente en jueces como Scalia entre los conceptos de culpabilidad y mens rea referida a la distinción entre imputación subjetiva al tipo y culpabilidad.
} 
Paredes y Yusari - Menores de edad en la jurisprudencia de la Corte Suprema de EE.UU.

\section{iii. Los Estudios}

Aun si se aceptara el punto de vista de Scalia en Stanford como de sentido común, estudios recientes indican que la dinámica psico-social generalmente involucrada en actos de violencia juvenil es bastante más compleja y comparte muy poco con los estudios acerca de solución de problemas y toma de decisiones en un contexto de laboratorio. Esto sustentaría lo argumentado más arriba.

Así, se puede citar a Thomas Grisso ${ }^{8}$ quien sostiene: "los actos juveniles de bomicidio no implican necesariamente elecciones basadas en procesos de toma de decisión o solución de problemas. Ocurren más a menudo en razón de elecciones que llevan a situaciones que ofrecen un mayor riesgo de un encuentro agresivo. Las similitudes entre jóvenes y adultos en lo que respecta a estudios de toma de decisiones en contextos tradicionales de investigación no son generalizables a los procesos de toma de decisión relativo a las conductas delictivas. Por el contrario, adolescentes mayores manifiestan marcadas diferencias en relación con los adultos en lo que se refiere a la reacción en momentos de inseguridad y stress, donde factores no cognitivos, psico-sociales juegan un rol importante". En el mismo sentido, Gary Melton ${ }^{9}$ afirma que "Del hecho de que los niños tengan la capacidad de desenvolverse de manera competente y responsable no significa que ejercerán esa madurez de juicio, particularmente cuando las decisiones se toman bajo circunstancias de fuerte stress".

Además, dichas situaciones de stress pueden radicarse en condiciones de privación social e inestabilidades en el entorno familiar y afectivo del sujeto, las cuales incluso pueden tener relevancia en la composición psíquica más profunda del individuo. A este respecto, cabe destacar lo ingenuo que resulta discutir sobre el rendimiento del argumento de la juventud como atenuante, en circunstancias de que si jóvenes cometen delitos tan atroces como en los casos en cuestión, se puede pensar que existen problemas profundos, que un simple incremento de penas no va a solucionar. No habrá más disuasión, sino más ejecuciones.

En apoyo a lo anterior, existen afirmaciones dignas de destacar en los fallos de la Corte. El juez Brennan en su voto de minoría en Stanford v. Kentucky sostiene: “...el mismo paternalismo que nuestra sociedad expresa hacia la juventud y la dependencia que los fuerza a adquirir significa que la sociedad carga con una responsabilidad por la acción de sus jóvenes que no tiene por los actos de los adultos quienes son, al menos en teoría, libres de tomar sus propias decisiones. Así, el crimen juvenil...no es exclusivamente culpa del joven; las ofensas de los jóvenes representan una falla en la familia, el colegio y el sistema social, quienes comparten la responsabilidad por la juventud en América".

\footnotetext{
8 Grisso, Thomas, "Society's Retributive Response to Juvenile Violence: A Developmental Perspective", 20 Law \& Hum. Behav. 229, 1996, citado en : Logan, Wayne A., "Proportionality and Punishment: Imposing Life Without Parole on Juveniles”, Wake Forest Law Review, Vol. 33, 2001.

9 Melton, Gary, "Developmental Psychology and the Law": The State of the Art, 22 J. Fam. L. 445, p. 465 - 466, 1984, citado en idem.
} 
Además, junto con los datos sobre adolescentes en el death row expuestos más arriba aportados por la exposición del juez Brennan, es relevante destacar que Kevin Stanford fue transferido a la división adulta del sistema penal del distrito de Jefferson, aun cuando al momento de su crimen poseía: "un bajo nivel de internalización de los valores y la moralidad de la sociedad, además de carecer de habilidades sociales. A raíz de su entorno familiar caótico y falta de tratamiento, se ha socializado en conductas delictivas y es además emocionalmente inmaduro y susceptible de tratamiento si se hace de manera adecuada y a largo plazo mediante intervención psicoterapéutica y terapia basada en la realidad con miras a su socialización, junto con medicación en instalaciones residenciales. Además, tenía una historia de uso de drogas y carecia de un nivel de interacción social propio de su edad'.

\section{iv. La Disuasión}

En este momento es relevante retomar el tema de la disuasión tratado parcialmente por Kennedy.

La concepción de los adolescentes que tiene el juez Scalia no se condice con aquellos que efectivamente delinquen, al menos en lo que respecta a crímenes relativos a la vida o integridad, y son condenados a muerte. Probablemente, los sujetos que concibe Scalia no formaran parte de los death rows.

El juez Scalia pretende fundamentar la eficacia disuasiva de la pena de muerte en la consideración de impunidad por su minoría de edad que tuvo Simmons al momento de exponer el plan a sus amigos. Según dicho juez, la eliminación de la pena de muerte conllevaría un alza de los asesinatos y crímenes similares por parte de los menores. Aparte de que, como se verá más adelante, las estadísticas apuntan en otra dirección, resulta contra intuitivo pensar que la mayoría de los jóvenes se inhiben de asesinar debido a la posibilidad de su ejecución.

Lo expuesto en relación con la dinámica presente en la violencia juvenil y los condenados a muerte, en adición a lo señalado por Kennedy, hace dudar seriamente del potencial disuasivo de cualquier pena, sobretodo para casos como los de Thompson, Stanford, Wilkins y Simmons. Como se puede apreciar, un alto porcentaje de los adolescentes condenados a muerte o a alguna otra pena referida a delitos de alta gravedad como los presentes carecen de aquellos atributos esenciales para poder fundamentar legítimamente la culpabilidad y la subyacente vinculación con los valores sociales que se les exige a la hora de castigarlos. Es problemático sostener que la reducción de penas incrementará el número de jóvenes que cometen actos criminales de gravedad, puesto que quienes los realizan son justamente aquéllos para los que las normas morales y penales, además de la conminación de sanción que las acompañan, no tienen efecto relevante. En este sentido no se materializaría el riesgo sustentado por O' Connor y Scalia de dejar sin el "adecuado" castigo a jóvenes que muestren la misma densidad moral y culpabilidad de un adulto. 
Paredes y Yusari - Menores de edad en la jurisprudencia de la Corte Suprema de EE.UU.

En efecto, se podría considerar que los adolescentes con una capacidad moral sobresaliente o igual a la de los adultos responsables y maduros no cometerán delitos graves como los comentados. Si tienen la capacidad de discernimiento moral elevada de los adultos seguramente no cometerán esta clase de delitos, por lo que si lo hacen, al menos prima facie se podría sostener que no tienen las capacidades que fundan la culpabilidad. Cualquier poder disuasivo no debería tener injerencia en ellos puesto que se abstienen de cometer delitos por consideraciones ajenas a la conminación penal. Por su parte, para los carentes de la moralidad necesaria, la conminación penal (cualquier sea la pena) presumiblemente no tendrá mayor efecto. Lo anterior claro, a menos que se fije el estándar de culpabilidad en características básicas y elementales presentes en cada ser humano con independencia de su condición.

\section{v. La Dinámica de la Alta Penalidad Juvenil}

En relación con lo anterior, Wayne Logan ${ }^{10}$ comienza uno de sus artículos constatando una dinámica propia de estos días: "Diariamente somos advertidos de un nuevo grupo de jóvenes "súper predadores" que está extendido en América, cometiendo actos de depravada brutalidad aparentemente sin ninguna consideración. Aün peor, los expertos sostienen que el tiempo se está agotando: algo se debe hacer ya ante una ola criminal de proporciones sin precedentes se acrecienta debido a inminentes alzas agudas del numero de dichos criminales. En este clima de ansiedad, cada trágico acto de violencia juvenil que recibe tribuna en los medios alienta renovados esfuerzos en los politicos en orden a hacer a la justicia juvenil más punitiva, con las consideraciones de eficacia encontrándose con "oídos sordos" e ignorando completamente la disminución significativa de criminalidad juvenil violenta"

De acuerdo lo anterior, el autor cita una serie de estudios que demuestra la caída en arrestos de jóvenes por crímenes violentos, desacreditando la imagen de los actuales "depredadores sin remordimiento", indicando que los jóvenes hoy en día no cometen más crímenes que los de una generación anterior. Además, los debates actuales ignoran el hecho de que los arrestos juveniles por crímenes serios no superan el $18 \%$ de todos los arrestos juveniles y que los arrestos por asesinato y violación no alcanzan siquiera un $7 \%$ de total de arrestos juveniles.

En distintos estados donde se ha mantenido un régimen comparativamente menos severo de penas que el común de los demás estados se han exhibido favorables cifras de delincuencia. Lamentablemente, dichas estadísticas han pasado a un segundo plano y ha aumentado la presión por incrementar el rigor de las penas a raíz de hechos criminales puntuales de gran conmoción pública. Se hace difícil argüir las favorables cifras de criminalidad en orden a mostrar cómo las políticas surten mejores efectos en términos agregados, por lo que no debiesen ser juzgadas por eventos aislados y particulares, sin evidencia de ser atribuibles a

\footnotetext{
${ }^{10}$ Logan, Wayne A., op.cit.
} 
dichas políticas ${ }^{11}$. Gracias a la actual psicología social y cognitiva se sabe que las experiencias vívidas pesan de manera desproporcionada en el juicio de las personas, quienes no son muy susceptibles a dejar que las estadísticas agregadas tengan el efecto que corresponde en sus opiniones espontáneas ${ }^{12}$. Lo anterior constituye otro argumento en contra a la regla caso a caso avanzada por O' Connor.

Por otra parte, Phillip Petit ${ }^{13}$ realiza una explicación bastante ilustrativa de este fenómeno apoyándose en la obra del historiador Oliver MacDonagh, Revolution in Government relativa al surgimiento del Estado Administrativista en el siglo XIX post revolución industrial. Pettit hace una analogía del proceso descrito en esta obra con la que según él existe en el incremento de penas, denominándolo "The Outrage Dinámic".

Este proceso se caracteriza en esencia por tres requisitos. Los primeros dicen relación con el acceso de la sociedad a canales de comunicación masivos donde sea efectiva la exposición de un mal. Además, los valores de la sociedad deben ser coincidentes con un sentimiento de ultraje o indignación ante dicho mal. Por último, es fundamental la organización democrática de la sociedad a fin de que los políticos sean permeables (en atención a consideraciones electorales) a la voluntad de la gente, de forma tal que deban responder de manera más o menos convincente y persuasiva a dicha indignación. Para Pettit, lo anterior desemboca en presiones que inciden fuertemente en la política criminal dada la condición de males sociales que presentan los crímenes.

Luego de la ocurrencia de algún crimen de características particulares que produce una fuerte indignación por el mal causado a una víctima inocente, los medios los utilizan para incrementar su audiencia mediante la exposición pública del hecho, presentándolo como un fenómeno masivo. Para Pettit, lo que en la época de la revolución industrial eran sentimientos humanitarios ante el trabajo infantil o las condiciones de las fábricas (provocando el aumento de tamaño del Estado para brindar protección), en las sociedades modernas es un sentimiento bastante más instintivo y básico ante la exposición de la criminalidad, generalmente tomando el carácter de venganza. Dado lo anterior, el tercer paso es la reacción de las autoridades públicas quienes, para mantener su credibilidad y posición, deben tener una actitud que exprese empatía ante los sentimientos de la sociedad. Por ello, deberán mostrar igual indignación y disposición a tomar las medidas que se encuentren a su alcance.

\footnotetext{
${ }^{11}$ Pettit, Phillip, “Is Criminal Justice Politically Feasible?”, Buffalo Criminal Law Review, vol. 5: 427, 2002 .

12 Tversky, Amos y Kahneman, Daniel, "Judgements of and by Representativeness" en: Judgment under Uncertainty: Heuristics and Bias, Daniel Kahnemann et. al. eds., 1982 (citado en Pettit, Philip Idem).

13 Pettit, Phillip, Idem.
} 
Paredes y Yusari - Menores de edad en la jurisprudencia de la Corte Suprema de EE.UU.

Así, se puede esperar que la reacción generalizada sea el endurecimiento de penas, de modo de expresar la repulsión y horror social. Es más, la legislación no deberá servir efectivamente a ningún bien mientras alcance en dureza el sufrimiento que la sociedad estima adecuado infligir al sujeto.

En suma, se da una efectiva resiliencia de penas altamente severas, tornando este punto en un equilibrio. En opinión de Pettit, basado en Emile Durkheim, el castigo de los crímenes sirve a una importante función social relativa a la expresión de la desaprobación colectiva de la sociedad, lo cual lo hace en cierta medida inmune a la política racional. Como se verá, esta función expresiva es inherente a la pena como atribución de sentido, sin embargo, esto no implica necesariamente la severidad desproporcionada de ésta. Lo anterior podría fácilmente constituir una cara de la explicación, quizás la más brutal, del sometimiento de los niños y adolescentes a la justicia penal adulta

A modo de conclusión de los apartados I y II es relevante preguntarse efectivamente en qué se funda la sindicación del menor como sujeto responsable penalmente. Ya Kennedy ha afirmado que los rasgos personales de los adolescentes en tanto categoría de personas implican que sus conductas delictuales no afirman necesariamente la peligrosidad de ellos en tanto sujetos. Así, en consideración a su peligrosidad disminuida, tampoco se justificaría su inocuización o aseguramiento extremo. De todos modos, si efectivamente se les reconoce capacidad de culpabilidad, aunque menor, en relación a ciertas condiciones morales que para el sistema están presentes incluso en niños de 10 u 11 años, el fundamento principal de su punición no debiese residir en su peligrosidad, lo cual parece ser realmente la razón en el caso de los adolescentes.

Por tanto, es contradictorio, tanto en la mayoría como en la minoría de la Corte, el debate en torno a la culpabilidad del joven con las consideraciones de su peligrosidad como fundamento predominante en la pena. A lo primero se relaciona la posibilidad de interactuar con el menor de una forma distinta a la que se hace con cosas o sujetos carentes de dicha capacidad moral, haciéndolos parte de un entorno en el cual los sujetos se reconocen recíprocamente como poseedores de caracteres morales que les permiten discernir entre las distintas conductas y reconocer lo que implican las relaciones intersubjetivas en la sociedad. Sin embargo, se niega dicho entendimiento en cuanto se pueden extraer de los considerandos de las sentencias fuertes influencias de la peligrosidad del sujeto como criterio legitimador de la sanción penal, por sobre una efectiva retribución en razón de la culpa o una adecuada medida de disuasión a futuros agresores.

Cabe asimismo cuestionarse la efectividad y legitimidad de penas severas como la muerte en lo que respecta a la retribución o disuasión, si es que realmente se pretende algo más allá del aislamiento o eliminación de un sujeto presuntamente peligroso. Si se afirma la culpabilidad y densidad moral suficiente de los jóvenes, o al menos de aquellos condenados a muerte, ejecutarlos o privarlos de libertad largamente debe justificarse en algo más que su peligrosidad, aunque se sostenga 
que ésta es un elemento integrante de la culpabilidad. Lo último, sin embargo, es altamente contradictorio con el razonamiento de la Corte, por cuanto intenta fundar su reprochabilidad en cierta aptitud moral y no en su peligrosidad.

Lo anterior, además de la caracterización que la Corte hace en estos casos de los adolescentes lleva a pensar que la pena en dicho sistema tiene simplemente la función de un aseguramiento cognitivo y no normativo. En ningún momento se debate en torno a la potencialidad de las conductas delictivas juveniles como un medio de puesta en peligro y erosión de las normas presentes en la sociedad. Ni siquiera es necesario preguntarse acerca del Derecho, pues basta por el momento considerar dicha situación en referencia a las normas y valores morales propios del contexto social. Una argumentación como las de Kennedy o Brennan en torno a los rasgos de los adolescentes debiese llevar a sostener que, para ellos, los adolescentes no pueden poner en duda y mostrar la misma irreverencia frente a los valores sociales que un adulto. No es claro cómo este aspecto pueda ser graduado en orden a situarlos dentro del sistema penal, pero en un rango inferior de penas (si es que efectivamente se puede sostener que abogar por la LWOP toma en consideración realmente dichas circunstancias). Sin embargo, es patente que para los jueces en general la culpabilidad en parte comprende el desafío que hace el joven en contra de las normas morales y los estándares de las relaciones interpersonales, por lo que realmente lo que se debe decidir es si los jóvenes efectivamente realizan dicho desafío y en definitiva pueden ser responsabilizados por esto. Al menos las estadísticas muestran que lo anterior no es plausible frente al grupo condenado por delitos graves debido a las carencias personales que evidencian.

Hay que destacar sin embargo, que esta especial consideración de la peligrosidad, al menos por el momento, no mueve el centro del juicio desde una ponderación retrospectiva a una prospectiva, puesto que en los términos que se plantea la discusión, dicha peligrosidad es determinante en la culpabilidad, la cual debe ser contrastada con la pena para hacer el juicio de proporcionalidad. Cuando la peligrosidad se utiliza para fundamentar una función intimidatoria adquiere el juicio carácter de prospectivo.

En suma, reuniendo todo lo expuesto en las páginas precedentes, se ve claramente cómo las penas impuestas a los jóvenes en Estados Unidos, en términos de proporcionalidad, no resultan ser idóneas, ciertamente no necesarias y como se ve, tampoco proporcionales en sentido estricto, tanto retrospectiva como prospectivamente. Así, se justifica un tratamiento diferenciado de los menores, el cual no consiste simplemente en impedir la ejecución para imponerles la LWOP o alguna pena privativa de libertad, al menos de larga duración.

\section{Derecho Penal y Culpabilidad: E1 Fundamento de la Exigencia}


Paredes y Yusari - Menores de edad en la jurisprudencia de la Corte Suprema de EE.UU.

\section{i. La Exigencia}

Dado que la Corte no vislumbra una exigencia democrática de legitimidad del derecho penal, fundando su justicia en que éste involucra solamente a ciudadanos, se puede sostener que es algo excesiva en el caso de adolescentes cuasi adultos que cometen crímenes de alta significación social. Sin embargo, aún queda por determinar efectivamente en qué dimensión de la persona, si no es su condición de ciudadano y por ende su potencial participación en la formación de las normas que lo rigen, se funda la legitimidad de su imputabilidad penal. Si como pretenden los jueces, en especial la mayoría de Stanford o minoría en Thompson y Roper, dicha imputación se legitima en la atribución de los adolescentes del status de persona en un sentido moralmente relevante, es de preocupar que aquellos jóvenes arrestados y condenados por delitos graves no posean dichos atributos en los que se debiese fundar su responsabilidad. Es más, parece de hecho profundamente injusto que se les castigue suponiendo ciertas cualidades morales que, en razón de su entorno familiar y social, les son materialmente imposibles de alcanzar.

En otros términos, lo que la Corte exige son ciertos atributos que permitan al sujeto imputable ser un interlocutor moral válido, aunque esto implique un nivel comunicativo menos sofisticado que aquél propio de la condición de ciudadano. Es evidente como en el sistema estadounidense la legitimidad de la vinculación a la norma no tiene una raigambre normativo-democrático sino que moral en sentido puro.

Además, más que la vinculación explícita con la norma de comportamiento que otorga el status deóntico de prohibido a cierto acto, se requiere cierta relación instrumental con la norma de sanción y una conexión más profunda con los valores sociales, la atención a la integridad del otro y un conocimiento adecuado de su humanidad y los principios que rigen las relaciones interpersonales. Parecen ser estas consideraciones y no las provistas por la norma de comportamiento las que deben incluirse, según la Corte, como directrices en el proceso de discernir actos de acuerdo a sus competencias. El deber de abstención proviene de la maldad intrínseca del acto y de sus valoraciones sociales, por sobre una consideración manifiesta de la norma penal. Lo más probable es que el valor de la norma y su función en la sociedad sea un aspecto relevante para los jueces, pero su argumentación no da muchas luces respecto de sus opiniones en este asunto.

Kindhäuser ${ }^{14}$ funda la justicia política de la pretensión de obligatoriedad del sistema jurídico frente al agente en su condición de ciudadano, rescatando así el mandato de neutralidad que debiese existir subyacente al Derecho. Como se dijo, su participación -al menos potencial- en la generación de la norma implica que debe considerarse a sí mismo como imperado y vinculado a ella, por cuanto de no serlo, incurriría en una contradicción performativa. Existen momentos

\footnotetext{
${ }^{14}$ Kindhäuser, Urs, op. cit.
} 
institucionales adecuados para controvertir la legitimidad de la norma, pero cuando se actúa como sujeto de derecho, lo que le corresponde a éste es simplemente la obediencia, pues su infracción expresa como sentido que la norma no es válida a su respecto, lo cual contradice la aceptación de ésta al momento de su generación.

Sin embargo, en el caso de los adolescentes o de todos aquéllos que no son ciudadanos, la obligatoriedad de la vinculación con el derecho penal debe tener otro sustento. Si no es así, simplemente se están ejerciendo medidas cognitivas violentas frente a alguien que se considera peligroso y que no comparte los valores de la sociedad. Por esto, si se pretende legitimar un derecho penal de nociudadanos se debe buscar un fundamento adicional que excluya la posibilidad de considerarlo ejercicio de violencia por parte de un grupo de la población que se ve amenazado por otro. En el fondo, es encontrar un sustento de la culpabilidad material distinto y más profundo que la deslealtad comunicativa o falta de fidelidad con el derecho.

Los jueces, quienes no controvierten la imputación de menores de edad en el sistema penal, sino que sólo la severidad de las penas, deben atribuirles la posibilidad de formar parte de interacciones donde se entablan pretensiones de validez sobre actos comunicativos. Como se dijo, dicha capacidad proviene de ciertas habilidades morales básicas presentes en los jóvenes que los proveen de las herramientas necesarias en contextos de resolución de problemas y tomas de decisión (a pesar de que, como se vio, aun esto es controvertible). La factibilidad de fundar expectativas de conducta que sean intersubjetivamente válidas, es necesaria para constituir una práctica que no se encuentre orientada simplemente de manera estratégica. Negar la posibilidad de tener expectativas frente a menores de 18 años, implica conducirse penalmente a su respecto de manera instrumental, lo cual está en contradicción con la afirmación de su capacidad moral para ser culpables.

\section{ii. Culpabilidad, Proporcionalidad y Retribución}

En el debate acerca de la proporcionalidad retrospectiva que llevan acabo los jueces (a pesar de que Scalia y los demás conservadores niegan la existencia del requisito de proporcionalidad de la VIII enmienda), existe acuerdo en cuanto a que para emitir dicho juicio, la medida de la pena debe ser contrastada con la culpabilidad del agente. En algunas intervenciones, O' Connor también afirma la vinculación de la pena con el merecimiento fundando en la culpa Lo anterior es concordante con la afirmación extendida de un derecho penal de culpabilidad.

Sin embargo, todos los jueces, en especial O' Connor y los conservadores otorgan discrecionalidad al estado en lo que respecta a la adopción de un fin de la pena en consideración a la evaluación que hagan de sus circunstancias sociales. En este sentido, la juez O' Connor afirma un criterio eminentemente prospectivo de proporcionalidad. Es así como sostiene que la pena es proporcionada y por ende aceptable, en tanto pueda razonablemente esperarse que contribuya, al menos en 
Paredes y Yusari - Menores de edad en la jurisprudencia de la Corte Suprema de EE.UU.

cierta medida, a las exigencias penológicas, cuya determinación forma parte de la esfera de atribuciones de cada estado. A raíz de esto, la culpabilidad perdería toda su capacidad de servir como constreñimiento deontológico al juicio de proporcionalidad, vislumbrándose en éste sólo consideraciones prospectivas ${ }^{15}$.

Lo anterior adquiere más asidero, por cuanto el apoyo de la jueza O' Connor a la mayoría para prohibir la pena de muerte a los menores de 16 años en Thompson v. Oklahoma proviene solamente de la constatación de la existencia de un consenso nacional en su contra, lo cual sumado a su batalla por impedir una prohibición categórica a la pena de muerte en Roper $v$. Simmons, hace pensar que, a su parecer, el criterio de la culpabilidad no ofrece mayores impedimentos al juicio de proporcionalidad en sentido estricto.

Los otros 4 jueces que concurren en la mayoría de Thompson utilizan el criterio de la consideración que tiene la sociedad acerca de la madurez de los menores de 16 en este caso. Para ellos, la prohibición que tienen de votar, servir en un jurado, conducir o casarse sin consentimiento de los padres, adquirir material pornográfico o de participar en apuestas legales, prueban aquella carencia de madurez que fundamenta su menor culpabilidad. De todos modos, al afirmar estos ejemplos, pero aun reconociendo la culpabilidad penal, deben necesariamente estar de acuerdo con Scalia, Rehnquist, Thomas y el resto en orden estimar que la culpabilidad penal implica condiciones de personalidad más elementales que aquéllas para participar de las actividades señaladas. Así, dicho reconocimiento de culpabilidad penal implica el reconocimiento de aquélla como cualitativamente distinta al nivel de madurez que funda las prohibiciones señaladas, tornando en espurios dichos ejemplo. Al sostener la existencia de culpabilidad penal al mismo tiempo de que utilizan los ejemplos señalados, conceden el punto a los conservadores.

De todos modos, lo anterior sirve para mostrar cómo la Corte pretende fundar la punición en la culpabilidad del menor. Habida cuenta de esto, como se dijo, se presentan ciertos problemas:

Si la imputación de responsabilidad se entiende como la carencia de cierto compromiso moral con los valores y normas sociales, debiese controvertirse una fundamentación prevencionista de la pena, sobre todo si para la Corte esta prevención es esencialmente negativa o intimidatoria.

\footnotetext{
15 Cabe destacar la distinción que se hace entre la pena capital y todas las demás, fundadas aparentemente en las características peculiares de la ejecución. Así, en Rummel v. Estelle (445 U.S. 263 1980) como en Harmelin v. Michigan (O’ Connor), se sostiene que el legislativo puede legítimamente aplicar criterios utilitaristas, aunque resulte retributivamente desproporcionado en los casos no capitales.
} 
Siguiendo a Mañalich ${ }^{16}$, pero tratando de adecuar su argumento a la realidad de la discusión de las sentencias, el reproche de culpabilidad se corresponde necesariamente con una actitud reactiva, la cual es incompatible con el mantenimiento de una actitud objetivante respecto del sujeto a quien se le reprocha la conducta incorrecta. En esta parte, sigue a Strawson ${ }^{17}$ para afirmar que la reprobación presupone la participación en relaciones interpersonales con otros, y en particular la consideración del destinatario del reproche como un participante en la comunicación. Por ende, si la práctica punitiva está fundada sobre esta clase de actitudes reactivas, lo cual forma parte de lo que se entiende como derecho penal de la culpabilidad, es imposible dar cuenta de dichas prácticas prescindiendo de dichas actitudes. Por ello, no se debe pasar por alto que prácticas como el derecho penal son realmente expresiones de las actitudes morales de los miembros de la comunidad y no sólo mecanismos que se utilizan de manera estratégica e instrumental. Lo anterior es lo que aparentemente olvidan O' Connor, Rehnquist, Scalia y los demás. En efecto, considerando la concepción que tiene O' Connor del juicio de proporcionalidad, además de la opinión expresada por Rehnquist en Harmelin v. Michigan (501 U.S. 957 1991), a saber: la proporcionalidad es inherentemente un concepto retributivo, por lo que adoptar un criterio de proporcionalidad a la luz de la $8^{a}$ enmienda implica imponer al estado una determinada concepción penológica de los fines de la pena, lo cual contraviene un ámbito propio de su discreción, se abre la puerta a que se elimine todo tipo de consideración orientada al reproche de culpabilidad y a la debida retribución. Esto es aun más grave en cuanto se considere el concepto de culpabilidad que maneja la Corte, íntimamente ligado a la peligrosidad, diluyéndose sus contornos específicos.

Atribuyéndole a la pena una función meramente disuasoria, el derecho penal pierde el elemento de la culpabilidad como determinante de su esencia, en tanto fundamento y límite. En definitiva, esto implica instrumentalizar al sujeto penado, pasando por alto cualquier tipo de consideración acerca de su situación particular en relación con el delito, utilizándolo sólo con una pretensión estratégicodisuasiva en relación con los demás posibles infractores y él mismo en el futuro.

Por esto, Mañalich siguiendo también a Strawson sostiene la incompatibilidad entre el reproche (reacción) y la adopción de una actitud objetivante, en tanto se aprecia al otro como un "objeto de la táctica social", como un individuo sujeto a tratamiento, respecto del cual hay que adoptar, eventualmente medidas preventivas. Así, la suficiente capacidad moral que Scalia atribuye a los adolescentes en orden a fundamentar el reproche por el crimen cometido es absolutamente incompatible con la afirmación de la disuasión como eventual único fin de la pena. Al dejar a la discrecionalidad del estado la inclusión

\footnotetext{
16 Mañalich Raffo, Juan Pablo, "Pena y Ciudadanía”, pp. 6 y siguientes. Artículo presentado en el II Congreso de Derecho y Teoría Constitucional, año 2005. Publicado en REJ n ${ }^{\circ}$ 6, Facultad de Derecho, Universidad de Chile, Santiago, 2005.

17 Strawson, P.F., Libertad y Resentimiento, Paidós, Barcelona, 1995, p. 47 (citado en Mañalich idem.).
} 
Paredes y Yusari - Menores de edad en la jurisprudencia de la Corte Suprema de EE.UU.

de la retribución como fin de la pena (o desfigurando dicho concepto) con miras a negar la necesidad del requisito de proporcionalidad a la luz de la VIII Enmienda, priva al derecho penal completamente del requisito de culpabilidad que le corresponde. La proporcionalidad fundada en el reproche por culpabilidad es necesaria si se quiere ser coherente con el reconocimiento del adolescente como un sujeto que comparte una posición en cierto estadio de comunicación moral con el resto de la sociedad. Al permitirse la adopción de fines meramente disuasivos, se desconoce esa capacidad del menor para formar parte plenamente de la interacción social. Así, Strawson señala que la adopción de actitudes de desaprobación e indignación son precisamente correlatos de la demanda moral cuando se siente que la demanda ha sido ignorada ${ }^{18}$. Por ello, en todo momento debe procurarse el reconocimiento de dichas circunstancias si es que realmente el reproche penal se funda en la culpabilidad.

De este modo, resulta difícil entender el planteamiento de Kennedy en Roper $v$. Simmons, puesto que considera que los adolescentes carecen de ciertas cualidades morales que los incapacitan para integrarse en un sistema de interacción social en igualdad de condiciones con los adultos, pero sin embargo son sujetos pasivos de todo el peso del ius puniendi estatal, sólo que no respecto a la pena más grave de todas, en consideración a ese margen deficitario en comparación los adultos. Como se señaló, es muy confusa la utilización de ejemplos de otros ámbitos del Derecho que hacen Kennedy y Brennan a la hora de sostener el déficit de madurez de los adolescentes, pues a raíz de éste no se les permite involucrarse en actividades que ciertamente requieren niveles de sofisticación mayores que el discernir el bien del mal, pero a la vez se justifica que caiga sobre ellos todo el peso del poder punitivo del Estado con la totalidad o casi la totalidad de sus consecuencias lesivas. En cierto sentido, el derecho penal es una práctica mucho más compleja que votar o adquirir pornografía, la cual requiere ciertos atributos cualitativamente distintos. El derecho penal supone una práctica en la que se reconocen mutuamente los sujetos la capacidad de formar parte de interacciones orientadas al entendimiento, entendimiento que para la Corte lo constituye básicamente la capacidad de discernir entre bien y mal. En este sentido, es más coherente Scalia y los demás jueces que brindan a los jóvenes el mismo status de los adultos, justificando así la igualdad de las sanciones penales. Sin embargo, pierden coherencia a la hora de olvidar la función retributiva y correspondiente proporcionalidad necesaria de la pena, pues no tiene sentido discurrir acerca de la culpabilidad si luego ésta se olvida a la hora de darle la importancia a la disuasión. Incluso el otro grupo de jueces peca de lo mismo al analizar la eficacia disuasiva de las penas en los menores de edad.

\footnotetext{
18 Ibid pág. 63.
} 


\section{iii. Pena y Persuasión}

Pablo de Greiff ${ }^{19}$ afirma que lo que distingue a las posiciones expresionistas es que se centran en el castigo como una expresión de condena, en lugar de una herramienta de disuasión o de incapacitación del delincuente. Aun más, toman esta expresión no sólo para capturar el significado de la pena sino que por si misma para justificar la práctica. Dado que no se puede sostener que el objeto de la pena es simplemente expresar un juicio sin considerar si existe algún tipo de respuesta (puesto que la racionalidad instrumental, la necesidad de existencia de un fin en la pena -el cual no tiene por qué ser única o predominantemente preventivo- es inherente a una práctica punitiva moderna con exigencias de efectividad)... se afirma que el fin del castigo es persuadir a los delincuentes y a las demás personas de la sociedad acerca la injusticia de ciertas conductas. Para De Greiff, esto viene dado por la teoría comunicativa del castigo.

De todos modos, en contra de lo que se pudiese pensar, De Greiff, sostiene que dicha concepción del castigo no es reduccionista, toda vez que: “...el tipo de expresionismo sustentando aqui satisface dicho requisito: insiste en que una seria inmoralidad es condición necesaria del castigo, pero reconoce que, además de la persuasión moral de los delincuentes, la culpa y castigo pueden servir otros fines sociales, tales como la prevención. En efecto, el expresionismo se articula en una sofisticada relación con la disuasión. Asi, la disuasión no justifica-al menos por si sola- el castigo, pero eso no quiere decir que los expresionistas sean indiferentes a los potenciales efectos disuasivos de la pena. Ellos sostienen que la pena se justifica como forma de prevenir los crímenes, sólo en tanto pueda enseñar a los criminales y público en general las razones morales para elegir la abstención de cierto delito". Es patente así la concepción positiva de la disuasión que tiene De Grieff, entendiéndola a diferencia de la Corte, como prevención general positiva. Esta es compatible con la función expresiva y con la atribución de los participantes de la práctica de cierta densidad que hace posible su persuasión.

A pesar de que no quedan claro exactamente los límites de la retribución y prevención general (negativa o positiva) en esta concepción de la pena, es sin embargo útil analizar el planteamiento de Scalia a la luz de ésta.

La persuasión se puede dar sólo entre sujetos que participan de una práctica común en la cual es posible la interacción comunicativa orientada al entendimiento entre ellos. Deben compartir una base argumentativa de modo que puedan interpelarse, debiendo existir un sustrato mínimo compartido que los hagan mutuamente permeables a los actos de habla con pretensiones de comprensión y validez. De este modo, “... el punto no es solamente que al culpar a alguien simplemente alegamos que existen razones morales en virtud de las cuales debió haber evitado actuar como lo hizo, sino que ofrecemos esas razones a él. Al culpar a alguien nos

\footnotetext{
${ }^{19}$ De Greiff, Pablo, "Deliberative Democracy and Punishment", Buffalo Criminal Law Review, 2002, p.375.
} 
Paredes y Yusari - Menores de edad en la jurisprudencia de la Corte Suprema de EE.UU.

involucramos con él en una discusión moral cuyo fin es lograr que acepte nuestro juicio acerca de su acción" 20 .

Para Scalia, jóvenes y adultos comparten ciertos atributos que les permiten involucrarse mutuamente en una práctica argumentativa moral con pretensiones de validez, donde comparten una comprensión de determinados aspectos de la vida y toman una posición igual frente a éstos. Esto se traduce en que Scalia estime que ambos grupos son igualmente capaces de culpabilidad. Así, debiese admitirse la posibilidad de persuasión mediante los interlocutores.

Sin embargo, el juez conservador niega esta posibilidad al aceptar a la disuasión como eventual único fin de la pena. En este sentido adopta una posición completamente instrumental hacia el sujeto, claramente sin pretender su persuasión, como tampoco de los demás miembros de la sociedad. Además, dicha persuasión de ser posible, carece de todo efecto cuando al sujeto se le confina permanentemente o se le ejecuta.

En el caso de los menores, se busca que con la dureza de las penas se inhiban de cometer ciertas conductas -recayendo todo el peso en la norma de sanción- la cual por esencia no puede persuadir, si no que simplemente intimidar y guiar una conducta estratégicamente orientada. Los jóvenes no necesitarían así persuadirse de la maldad de sus actos o de las expectativas que la sociedad tiene de ellos, sino que sólo deben temer lo suficiente a la pena para que se abstengan de hacerlos. No se vislumbran funciones de la pena orientadas al entendimiento. Ciertamente Scalia no debe desconocer que es inevitable la expresión de sentido inherente a la pena, pero éste no tiene relevancia en las consideraciones de dicho juez sobre los jóvenes como participantes en igualdad de condiciones que un adulto de la "práctica moral". Además, la retribución parece ser en la sentencia el infligir el sufrimiento provocado como forma de talión, más que una expresión de reproche o indignación por el acto dirigida al delincuente como ser moral igualmente capaz, quien ha defraudado las expectativas que cifraba la sociedad en él al reconocerle dicha igualdad. Al delinquir, la retribución de la pena debiese expresar y hacer patente la contradicción incurrida por el sujeto al no actuar conforme a su capacidad moral. En lugar de eso, la faz retributiva para los jueces dice relación solamente con aplicar al sujeto un mal comparable al de la víctima, fundado a su vez en la depravación o maldad de carácter. De este modo, ni la retribución ni la prevención están, en el entender de la Corte, orientadas a dicha persuasión implicada por el reconocimiento de cierto status moral a los adolescentes. A éstos, o se les intimida o se les incapacita.

En el caso de los que abogan por la prohibición de la pena de muerte a los menores, la situación es exactamente la misma. Para ellos, los jóvenes carecen de igualdad con los adultos en el plano de la madurez, por lo que no son interpelables de igual manera. Sin embargo, esto no se traduce para los jueces en un déficit de

${ }^{20}$ Ibid. p. $389-391$. 
posibilidades de persuasión, sino que en una ineficacia disuasoria, en el sentido de que dicha incapacidad juvenil los hace menos susceptibles a ser objetivizados y a conducirse ante ellos de manera instrumental. Como se dijo, no se ve como esa constatación no se hace extensible a la LWOP u otras privaciones de libertad.

Considerar a los jóvenes participantes iguales con acceso a los valores y normas de la sociedad daría un efectivo sustento y legitimidad a la exigencia de vinculación y obligatoriedad con el Derecho Penal. Dicha comprensión podría tornar innecesaria la fundamentación democrática de la pena, en tanto se les reconoce a los jóvenes una participación igualitaria en la dimensión que ofrece sustento al Derecho Penal. Cuando el derecho penal se fundamenta y legitima democráticamente, se deriva necesariamente la injusticia e ilegitimidad de su aplicación a quienes no son ciudadanos. Es más, en este punto dejaría incluso de ser efectivamente Derecho Penal. Sin embargo, cuando su legitimación proviene de otra dimensión del individuo, no ya de su ciudadanía, sino que como persona en un sentido moralmente relevante, es legítima su imposición a todos quienes participen de este carácter de persona con cierta densidad moral. Al parecer esto es lo que pretende hacer la Corte. A pesar de ello, ésta no adopta todas las consecuencias necesarias de dicho planteamiento al fundar su culpabilidad en ese status de persona moral, pero no atribuyéndole lo que le corresponde al individuo en virtud de esa posición.

\section{iv. Los Fundamentos de Justicia}

En definitiva, hay al menos dos formas de comprender el crimen y la pena. Ambas se encuentran expuestas en Lifting the Veil on Punisbment de Stephen P. Garvey $^{21}$. Una de ellas esté influida por la concepción de los sujetos propia de la filosofía liberal contractualista, en especial en lo que respecta a la visión de los sujetos tras el velo de la ignorancia rawlsiano. Esta visión de los "contratantes" implica que el crimen es una violación intencional de los derechos de un ciudadano a manos de otro. Constituye así un incumplimiento del contrato por el cual el agresor debe pagar los daños previamente acordados mediante un castigo. De este modo, el castigo es un ejercicio instrumental de coerción necesario para alcanzar fidelidad al Derecho en términos perlocucionarios, o sea, obediencia. La severidad o dureza del castigo es el precio que acordó pagar el ofensor en orden a mantener un sistema de disuasión racional, sujeto a ciertos constreñimientos marginales. El miedo es fundamental. Las víctimas temen ser re victimizadas. Las víctimas potenciales temen convertirse en victimas actuales. Los agresores deben temer el prospecto de verse atrapados y penados.

Sin embargo, para Garvey existe un panorama alternativo, el cual presupone una conexión más profunda entre los contratantes: “... presupone que los contratantes se respetan los unos a los otros, no como un falso sentido de respeto construido en base al desinterés mutuo e ignorancia, sino que respeto genuino. Los miembros de esta comunidad

\footnotetext{
${ }^{21}$ Buffalo Criminal Law Review, Vol. 7 :443, 2004.
} 
Paredes y Yusari - Menores de edad en la jurisprudencia de la Corte Suprema de EE.UU.

se respetan porque se consideran mutuamente como poseedores de una igualdad dignidad (en un sentido moralmente más profundo que la posesión de un esquema igualitario de libertad y derechos subjetivos)".

Esta dignidad común le asegura a cada uno ser tratado de cierta manera y no de otra. Por ende, aquéllos que intencionadamente violan su seguridad o integridad los tratan de una manera inconsistente con dicha dignidad. De este modo, el crimen y la pena adquieren una dimensión de sentido no meramente instrumental, en razón a que la comisión de un crimen es más que una violación de derechos que debe ser disuadida, pues implica un desprecio por la dignidad e igualdad moral de la víctima, expresando así una demanda de superioridad moral.

Dicha comprensión, como se ve, no es difícilmente reconducible a la teoría comunicativa de Kindhäuser de raigambre habermasiana, solamente que esta versión se da en un plano más explícitamente moral El razonamiento anterior parece ser más acorde a lo que se conoce como delitos malum in se. En los casos relativos a delitos malum probibitum, el análisis requeriría sostener, asumiendo que queramos tratar a dichas conductas como merecedoras de pena, que la ley en sí misma tiene cierta dignidad y que por lo tanto le corresponde cierto respeto, por lo que un sujeto que desafía a la ley muestra desprecio por ésta. Además, necesita describir las condiciones bajo las que a la ley le corresponde dicha dignidad y respeto $^{22}$. Dicha dignidad puede fundamentarse de diversas maneras, siendo una de éstas su generación democrática, tal como lo hace Jeremy Waldron ${ }^{23}$. En este momento, es clara la conexión entre esta teoría y la sostenida por Kindhäuser acerca del fundamento y legitimación de la imputación a la culpabilidad como deslealtad comunicativa mediante un desafío de la norma válida.

De este modo, el sentimiento predominante en la víctima no es el miedo, sino que el enojo y el resentimiento, tal como lo sostenía Strawson. Así, el crimen es una afrenta a la dignidad de la víctima, ante la cual los demás miembros de la sociedad que se identifican con ella expresan también su sentimiento de indignación y resentimiento. Por lo tanto, se puede sostener que una comunidad como ésta, el castigo no es simplemente un mecanismo preventivo o de disuasión, sino que primordialmente un medio institucionalizado de condena y censura. $\mathrm{Al}$ mismo tiempo, el castigo alcanza ciertas metas, como la restauración del igual valor moral de la víctima, aplaca la voluntad desafiante y despectiva del agresor y anula el falso mensaje atribuido como sentido a la conducta del delincuente. De todas formas, lo anterior también implica que la identificación corre no sólo con la víctima, sino que también con el delincuente. El trato entre los miembros de la comunidad en virtud de esta teoría, deja de ser el que se da mediante extraños, existiendo una conexión más profunda con los otros.

\footnotetext{
22 Garvey, Stephen, ibid. p. 461.

${ }^{23}$ Waldron, Jeremy, The Dignity of Legislation, Cambridge University Press, U.K., 1999.
} 


\section{Conclusión}

Habidas las características que se presentan en los menores de edad como categoría, es especialmente relevante examinar la plausibilidad de sindicarlos como sujetos válidos de una interpelación penal. Como se ha evidenciado a lo largo de la exposición precedente, la tratativa que hace la Corte Suprema Estadounidense en relación a la punibilidad de los menores de edad presenta numerosas deficiencias argumentativas. Merece una crítica particular la incapacidad de los jueces de hacerse cargo cabalmente de las conclusiones que exponen.

Las sentencias estudiadas admiten que por regla general a los menores de edad les asiste una menor reprochabilidad por sus actos, asentada en una culpabilidad reducida. Para sostener esto, la Corte se sirve de argumentos que aluden a la menor responsabilidad, reducida capacidad volitiva, falta de carácter y vulnerabilidad motivacional de esta categoría de individuos.

Quedan sin embargo muchas dudas. Se desconoce las razones por las cuales esta menor culpabilidad, aunque no sirva para fundamentar la imposición de la pena capital, sí sea útil en opinión de los jueces para apoyar otras medidas coercitivas extremadamente lesivas como la LWOP y que tienen las mismas consecuencias que la primera: inocuizar al sujeto. Para descartar la pena de muerte se afirma que los adolescentes tienen rasgos de personalidad transitorios que son susceptibles de ser cambiados. Es a lo menos dudoso sostener que esta premisa se salvaguarda sólo evitando la imposición de la pena capital. En general, en lo relativo a un menor de edad, cualquier pena gravosa significará privarle de su potencial de desarrollo. Se asume el razonamiento parcialmente. Se rechaza la pena de muerte por su naturaleza particular de ser irreversible y de extinguir el potencial de madurez de un menor problemático y disociado, pero la evidencia señala que cualquier pena penal de cierta magnitud ejerce sobre el adolescente el mismo efecto.

La adopción parcial de este dato evidente se desprende de consideraciones políticas, como se mencionó anteriormente, así como de ciertas confusiones conceptuales.

La primera de ellas dice relación con la superposición de la peligrosidad de un individuo al reproche que le asiste por un acto particular atendiendo a sus circunstancias personales. El sistema estadounidense permite la ponderación en un mismo estadio de todas estas consideraciones. El jurado tiene la facultad de libre ponderación de todas estas variables, adquiriendo normalmente más peso las consideraciones relativas a la atrocidad del hecho, la peligrosidad del sujeto y los eventuales efectos intimidatorios de las penas. Esta solución, como se expuso, contradice los fundamentos de la reprochabilidad moral del adolescente en tanto subyace como una justificación a la pena de los menores de edad como no ciudadanos. 
Paredes y Yusari - Menores de edad en la jurisprudencia de la Corte Suprema de EE.UU.

No se explica cómo la Corte, adhiriendo a una posición que funda la reprochabilidad de una conducta a un adolescente en su responsabilidad moral, no comparta al mismo tiempo una idea de la culpabilidad que se refiera a las capacidades morales del agente. Esto se desprende de los argumentos de los jueces conservadores, especialmente de las exposiciones de Scalia, quien parece no distinguir entre la capacidad para entender a la bondad o maldad de una acción y la facultad de los menores de edad para adecuar consciente y responsablemente su comportamiento a tales estándares.

Un juicio de proporcionalidad estricto retrospectivo al que sirva de base la culpabilidad implica aceptar que en los menores de edad se da normalmente un fenómeno contradictorio. Esto es, que aquellos sujetos que cometen acciones que provocan un mayor nivel de indignación social (malum in se) es a los cuales normalmente les asiste menor culpabilidad, radicada por regla general en un atrofio social derivado de su ambiente más cercano.

En segundo lugar, se logra desprender de las sentencias una constante alusión al fin disuasivo de la pena. Referirse a una concepción que instrumentalice al individuo significa per se desconocer su carácter de agente moral válido derribando el propio fundamento que sirve para sustentar, en opinión de la Corte, la culpabilidad de los menores de edad. Como se vio en su oportunidad, para ser totalmente consecuente con dicha proposición es necesario reconocer la función expresiva de la pena de modo tal que aquél interpelado por una infracción a la norma penal, sea reconocido por el sistema como un individuo capaz de comunicarse moralmente.

En definitiva, no se pretende sostener que se deba ser indiferente frente a los adolescentes o niños que cometan crímenes graves como los expuestos. Las carencias sociales, afectivas o psíquicas de alguien no derivan necesariamente en que puedan habitar en una comunidad en un constante desprecio y ataque a la dignidad e integridad ajena. Es justificado hacer algo al respecto de todos aquellos que dañan a otros más allá del límite tolerable por la interacción social. Sin embargo, los distintos modos de intervención deben justificarse diferenciadamente y habida cuenta de las cualidades especiales que se reconocen a los sujetos que se intervienen. Si se afirma que los adolescentes son igualmente capaces de culpabilidad que los adultos y se pretende fundamentar un derecho penal de la culpabilidad, no puede dejarse este aspecto de lado para que pasen a ser determinantes consideraciones acerca de la disuasión o la peligrosidad. Acordada dicha igualdad, la intervención debe dirigirse a ellos considerando debidamente sus atribuciones morales.

Si éste no es el caso, es preferible que se expliciten las razones que los hacen ser objeto de la intervención del Estado con el objeto de asegurar a la sociedad de su peligrosidad, a través de medidas de seguridad y no penas, por cuanto las últimas implican un reproche sin sentido en alguien que no se le reconoce la posibilidad de ser reprochado. Esto, por no compartir aquella 
densidad moral que lo hace susceptible a ser interpelado por un reproche penal. A su respecto, se puede actuar tácticamente con una fuerte intensidad, pero se debe ser consciente de la particular dimensión de sentido que la intervención conlleva.

Asimismo, es perfectamente aceptable que la culpabilidad no se funde en la dimensión ciudadana democrática del individuo, sino que en un ámbito moral común entre personas, provisto por su determinado status moral. Sin embargo, si se toma esta opción de igualdad de carácter de jóvenes y adultos, se deben llevar adelante todas las consecuencias que esto implica. Si no, es lisa y llanamente mejor sostener que frente a los menores no se actúa normativamente, sino que de forma cognitiva a raíz de su peligrosidad puesto que carecen de aquellos atributos que hacen exigible en un sentido relevante su vinculación con el Derecho. Si se sostiene que los menores no comparten una posición en ese ámbito que legitima la vinculación con el Derecho, es justificado interactuar en términos instrumentales con ellos, pero siempre en respeto de la dignidad que poseen en tanto personas y otorgándoles la posibilidad de reforma reconocida como factible por la inestabilidad de su carácter y falta de libertad.

Es evidente la posibilidad de fundamentar la justicia de la imputación penal en algo distinto que la ciudadanía, exigiéndose la vinculación a las normas por referencia a ciertos atributos morales que otorgan la capacidad de comprender lo que implica la humanidad y dignidad de los demás sujetos sociales, incorporando dicha comprensión en el plano de las relaciones intersubjetivas y la comunicación moral. A este respecto, tanto adolescentes como adultos pueden ser capaces de culpabilidad legítimamente. Así, se debe orientar la interacción en orden a que el sujeto se sirva de todas aquellas capacidades que posibilitan su comunicación moral en lugar de dirigirse ante éste sólo como un individuo instrumentalizable para cierto fin social. 
Paredes y Yusari - Menores de edad en la jurisprudencia de la Corte Suprema de EE.UU.

\section{BIBLIOGRAFIA}

- Chambers, Simone, "Democratizing Humility", Buffalo Criminal Law Review, Vol. 7:465, 2004.

- De Greiff, Pablo, "Deliberative Democracy and Punishment", Buffalo Criminal Law Review, 2002.

- Dolovich, Sharon, "Idealism, Disproportionality, and Democracy: A Reply to Chambers and Garvey", Buffalo Criminal Law Review, Vol. 7:479, 2004.

- Dressler, Joschua, Understanding Criminal Law, $3^{\mathrm{a}}$ Edición, Ed. Lexis Publishing (New York, EE.UU.) 2001.

- Garvey, Stephen, "Lifting the Veil on Punishment", Buffalo Criminal Law Review, Vol. 7 :443, 2004.

- Hassemer, Winfried, "Persona, Mundo y Responsabilidad”, en Persona, Mundo y Resposabilidad. Bases para una Teoría de la Imputación en el Derecho Penal, Temis, Santa Fe de Bogotá, 1999.

- Kindhäuser, Urs, "La Fidelidad al Derecho como Categoría de Culpabilidad”, en Revista Peruana de Doctrina y Jurisprudencia Penal, Lima, 2000.

- Logan, Wayne A., "Proportionality and Punishment: Imposing Life Without Parole on Juveniles", Wake Forest Law Review, Vol. 33.

- Mañalich Raffo, Juan Pablo, "Pena y Ciudadanía", en REJ no 6, Facultad de Derecho, Universidad de Chile (Santiago) 2005.

- Moore, Michael, Placing Blame, Ed. Oxford University Press, New York, 1997.

- Pettit, Phillip, "Is Criminal Justice Politically Feasible", Buffalo Criminal Law Review, vol. 5: 427.

- Piña, Juan Ignacio, La Estructura de la Teoría del Delito en el Ámbito Jurídico del "Common Law, Comares, Granada, 2002.

- Rawls, John, Teoría de la Justicia, Fondo de Cultura Económica, últ. Edición 1995, Ciudad de México.

- Robinson, Paul, Structure and Function in Criminal Law, Oxford University Press, 1997.

- Schuneman, Jakobs, Roxin, et. al, Sobre el Estado de la Teoría del Delito, Civitas, 2000.

- Waldron, Jeremy, The Dignity of Legislation, Cambridge University Press, U.K., 1999.

- Zaibert, Leo, Book Review de Punishment, Liberalism and Communitarianism de R.A. Duff. 